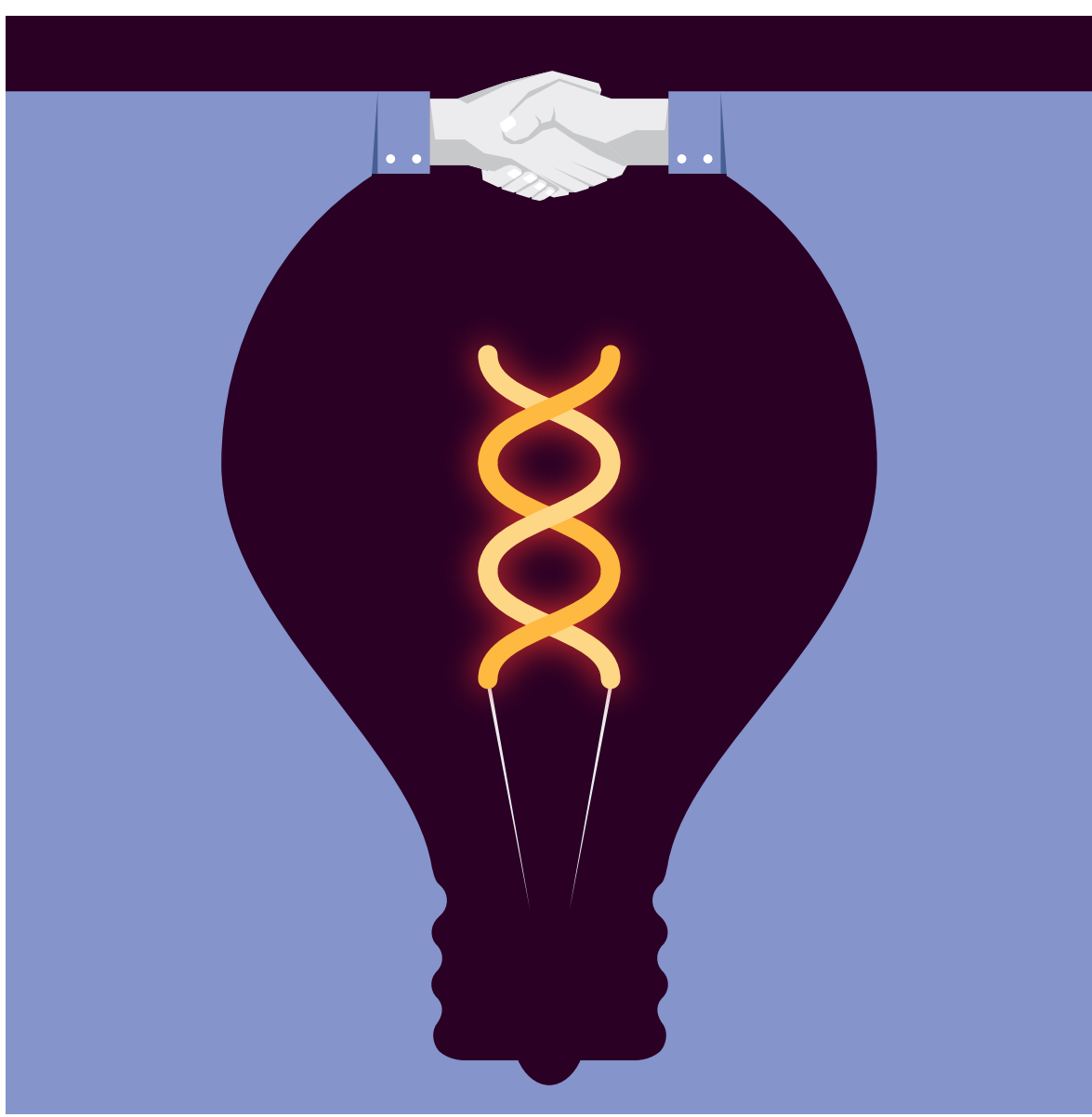

\title{
Pursuit of profit poisons collaboration
}

\section{The CRISPR-Cas9 patent battle demonstrates how overzealous efforts to commercialize technology can damage science, writes Jacob S. Sherkow.}

\section{$\mathrm{L}$} ast month, in an extraordinary dispute before the US Patent and Trademark Office (USPTO), university lawyers laid out their clients' legal strategies for claiming patents that cover the celebrated gene-editing technology CRISPR-Cas9. Over the next year, the USPTO will receive volumes of evidence centred on who first invented the technology.

Battles over scientific priority are as old as science itself. But the CRISPR-Cas9 patent dispute is unusual because it pits two leading research institutions against one another for the control and industrial development of a foundational technology: the University of California, Berkeley (UC Berkeley), and the Broad Institute of MIT and Harvard in Cambridge, Massachusetts.

As scientific institutions increase their involvement in the commercialization of research ${ }^{1}$, it is worth considering the potential consequences for science if more institutions follow the path of UC Berkeley and the Broad Institute.

\section{HIGH STAKES}

In May 2012, researchers at UC Berkeley, led by Jennifer Doudna and her collaborator, Emmanuelle Charpentier (then located at the University of Vienna in Austria) filed a patent application in the United States for CRISPR-Cas9. Seven months later, Feng Zhang, a researcher at the Broad Institute, filed a competing application that covered similar uses of the technology. After Zhang's lawyers requested that his application be fast-tracked, the USPTO awarded one patent to Zhang in April 2014, followed by a dozen more in the subsequent 12 months Meanwhile, the application made by Doudna and her colleagues languished.

Last April, Doudna's lawyers requested that the USPTO conduct a specialized legal trial, known as a patent interference, to determine the ownership of the US patents that cover the CRISPR-Cas9 system. This January, the USPTO formally agreed to carry out the proceeding.

One conspicuous aspect of this case, in my opinion, is the degree to which UC Berkeley and the Broad Institute have weighed in on what is essentially a dispute over scientific priority.

The Broad Institute has produced press releases, videos and a slick feature on its website that stress the importance of Zhang's contributions to the development of the CRISPR-Cas9 technology. And earlier this year, the central positioning of Zhang's work in a historical perspective of CRISPR published in $\mathrm{Cell}^{2}$ by the president and director of the Broad Institute, Eric Lander, prompted a storm of angry responses from scientists, including Doudna and Charpentier. Meanwhile, at UC Berkeley, a press release that discussed the potential of CRISPR described Doudna as "the inventor of the CRISPR-Cas9 technology" (see go.nature.com/cm2gvx).

The financial stakes are high. The CRISPR-Cas9 patents are widely viewed to be worth hundreds of millions, if not billions, of dollars. Both organizations have invested directly in spin-off companies that were cofounded by their researchers - the Broad Institute in Editas Medicine, co-founded by Zhang, and UC Berkeley in Caribou Biosciences, co-founded by Doudna. A report submitted by Editas in January to the US Securities and Exchange Commission lists the Broad Institute and other Harvard-affiliated institutions as owning a major equity stake in the company: about $4.2 \%$ of its common shares (see go.nature.com/45cley).

\section{DIFFERENT TIMES}

Efforts to commercialize the research output from universities played out differently in the past. Since 1980, US universities have been able to patent the inventions of their researchers, thanks to the Bayh-Dole Act legislation that determines the ownership of intellectual property arising from federally funded research. But for the most part, insti-

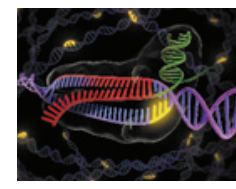

$\rightarrow$ NATURE.COM For more of Nature's coverage on CRISPR, see: nature.com/crispr tutions have kept their distance from disputes over scientific priority. In fact, after factoring in the costs of filing patents and staffing, university technologytransfer offices have generally been money losers for their institutions $s^{3}$. 
Even in the case of lucrative patents, commercial development has frequently been left to venture capitalists and the researchers themselves. Take the Cohen-Boyer patents, which covered early gene-splicing technology and netted Stanford University and the University of California, San Francisco (UCSF), both in California, hundreds of millions of dollars in licensing fees during the 1980s and 1990s. In this instance, Genentech, the company in South San Francisco, California, that was formed to commercialize the underlying technology, sprung from the efforts of Herbert Boyer, one of the founding researchers, and the financier Robert Swanson. The company was neither owned by, nor an exclusive licensee of, Stanford or UCSF.

Research institutions in general are starting to play a bigger part in shepherding their researchers' projects through the commercialization process. A 2014 report from the Association of University Technology Managers in Oakbrook Terrace, Illinois - an organization that supports managers of intellectual property at academic research institutions, non-profit organizations and government agencies worldwide - documented that universities are increasing equity investments in their researchers' start-up companies. Of the patent licences granted by universities in $2014,10 \%$ were tied to such investments ${ }^{1}$, compared with 6.7\% in 1999 (ref. 4).

I am concerned that such involvement in commercialization has the potential to clash with the broader, educational mission of research institutions.

Universities worldwide have long strived to foster a culture of scientific collaboration. Even when universities have obtained broad patents, as the Carnegie Institute of Washington in Washington DC did in the early 2000s for a gene-expression control technology known as RNA interference, licences have been cheap and easy for researchers to obtain $^{5}$. In other cases, scientists have simply ignored patents that cover fundamental technologies ${ }^{6}$.

Academic research institutions now seem less shy about taking each other to court for patent infringement. In 2011, the University of Utah in Salt Lake City sued the Max Planck Society for the Advancement of Science in Germany over claims to a patent that covered a technology called short interfering RNA, which inhibits gene expression (see go.nature.com/vyujnp). And over the past four years, Stanford University and the Chinese University of Hong Kong in Sha Tin have engaged in a heated patent litigation over prenatal genetic diagnostic blood tests, a market that was worth US\$530 million in 2013.

In the current era of budget tightening, universities of all stripes might be tempted to use licensing fees as another funding mechanism. The University of South Florida in Tampa, for example - a public institution that had
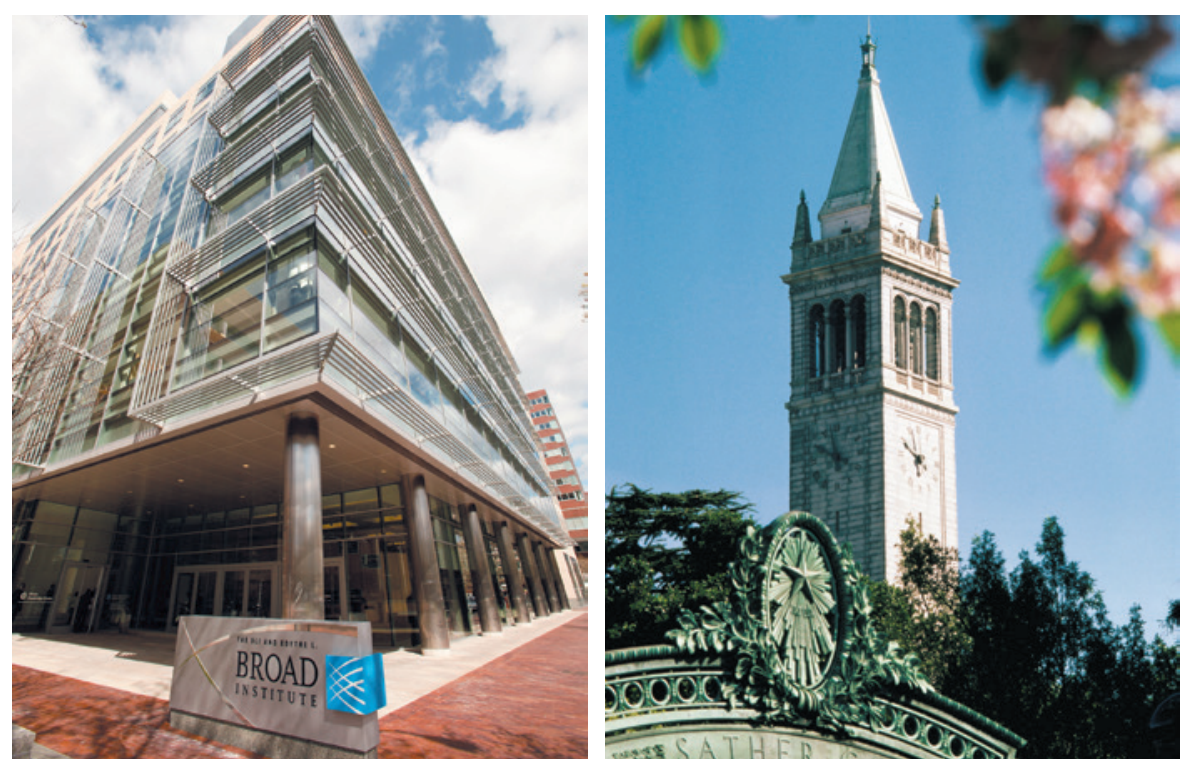

The Broad Institute of MIT and Harvard (left) and the University of California, Berkeley (right).

its state funding cut by $\$ 48$ million in 2012 - holds a substantial number of patents that have not yet been licensed and has a famously low ratio of patent-licence revenue to research expenditure ${ }^{7}$. If its financial situation were to deteriorate further, the university might be compelled to extract licence fees from other research institutions for those patents.

\section{PATH TO PROFIT}

It would be wrong to suggest that patents, writ large, are failing educational research institutions. In the cases of gene splicing, RNA interference and human embryonic stem cells, patents have been major earners for institutions and researchers without damaging the scientific enterprise ${ }^{5}$.

But an obvious danger of increasing the focus on commercialization is that educational institutions will view scientific research as a path to

"Efforts to
commercialize
the research
output from
universities
played out
differently in
the past."
profit, above all else. It is not hard to imagine that patent disputes might lead to university administrators pushing certain views on their scientists, denigrating collaboration with researchers from competing institutions and tasking tenure committees with valuing patents over publications.

Where scientific advances have the potential to be profitable, universities should support researchers to bring that work to fruition. This might include helping them to secure patents. But it is my view that serious commercialization efforts - such as granting exclusive licences or receiving equity ownership in researchers' start-ups - should be left to industry.

The CRISPR-Cas9 dispute could have played out very differently. Zhang and
Doudna were both co-founders of Editas. And UC Berkeley and the Broad Institute could have filed patent applications that listed the research teams from both institutions as co-inventors. Any resulting patents could then have been freely or cheaply licensed to other research institutions, or used to fund a joint academic organization dedicated to studying the technology. The patents could also have been widely, but not exclusively, licensed to a variety of industry competitors - promoting a robust, competitive market for commercial CRISPR-Cas9 applications and creating a funding stream for further academic research.

Biomedical research in educational institutions has long prided itself on a culture of openness and sharing — one that both Zhang and Doudna have exercised by donating various components of the CRISPR-Cas9 system to the open-science consortium Addgene in Cambridge, Massachusetts. The incentives that patents create for educational institutions should not be allowed to erode scientific collaboration.

Jacob S. Sherkow is associate professor of law, Innovation Center for Law and Technology, New York Law School, New York, USA.

e-mail:jacob.sherkow@nyls.edu

1. Association of University Technology Managers. AUTM US Licensing Activity Survey: FY2014 (AUTM, 2014).

2. Lander, E. S. Cell 164, 18-28 (2016).

3. Abrams, I., Leung, G. \& Stevens, A. J. Res. Mgmt. Rev. 17, 18-50 (2009).

4. Association of University Technology Managers. AUTM US Licensing Survey: FY1999 (AUTM, 1999).

5. Sherkow, J. S. Nature Biotechnol. 33, 256-257 (2015).

6. Eisenberg, R. S. Houston Law Rev. 45, 10591099 (2008).

7. Feldman, R. \& Price, N. W. II Stanford Tech. Law Rev. 17, 773-808 (2014). 